\title{
RANCANG BANGUN E-ARSIP AKREDITASI SEKOLAH
}

\author{
Inna Nur Atika ${ }^{1)}$ Zulfikar $^{2)}$ Primaadi Airlangga ${ }^{3)}$ \\ ${ }^{1,2,3)}$ Fakultas Teknologi Informasi Universitas KH.A. Wahab Hasbullah \\ Correspondence Author : ${ }^{1}$ zulfikardia@gmail.com ${ }^{2)}$ unwaha.primaadi@gmail.com
}

\begin{abstract}
Problems that occur in MI Negeri Kampungbaru Nganjuk current is the length of time to search for data that is archived in the map \& must open the sheet per sheet to find the desired data, the data sought sometimes incomplete and even missing data. This is because the data has not been stored in the database. The purpose of this study is to make the information system of accreditation archiving in MI Negeri Kampungbaru Nganjuk regency, where the archiving information system that was still manual to be a computerized information system. The formulation of the problem is how to design an information system of school accreditation archiving at MI Negeri Kampungbaru Nganjuk regency, and can make application program of school accreditation filing system at MI Country Kampungbaru Nganjuk regency.In the implementation phase, the system uses PHP programming language, as well as MySQL as its database.Based on the conclusions of the research results, the purpose of this program is Designing an application of an accreditation archiving system to help make it easier for schools to recover the necessary data.
\end{abstract}

Keywords: archiving information system, accreditation

\section{INTISARI}

Permasalahan yang terjadi di MI Negeri Kampungbaru Kabupaten Nganjuk saat ini adalah lamanya waktu untuk mencari data yang diarsipkan dalam map \& harus membuka lembar per lembar untuk menemukan data yang diinginkan, data yang dicari kadang tidak lengkap dan bahkan ada data yang hilang. Hal ini disebabkan karena data belum tersimpan dalam basis data. Tujuan penelitian ini untuk membuat sistem informasi pengarsipan akreditasi di MI Negeri Kampungbaru Kabupaten Nganjuk, dimana sistem informasi pengarsipan yang awalnya masih manual menjadi sistem informasi yang terkomputerisasi.Rumusan masalah adalah bagaimana merancang sistem informasi pengarsipan akreditasi sekolah di MI Negeri Kampungbaru Kabupaten Nganjuk, serta bisa membuat program aplikasi sistem pengarsipan akreditasi sekolah di MI Negeri Kampungbaru Kabupaten Nganjuk.Pada tahap implementasi, sistem ini menggunakan bahasa pemrograman PHP, serta MySQL sebagai databasenya.Berdasarkan tujuan penelitian ini adalah merancang suatu aplikasi sistem pengarsipan akreditasi untuk membantu mempermudah bagi pihak sekolah dalam menemukan kembali data-data yang diperlukan.

Kata Kunci : sistem informasi pengarsipan, akreditasi

ISSN Print $\quad$ : 1979-7141 


\section{Pendahuluan}

Perkembangan teknologi informasi yang semakin pesat membutuhkan sarana dan prasarana informasi yang lebih efektif dan efisien agar pengelolaan sebuah informasi dapat dilakukan dengan lebih teratur. Seperti yang diketahui, informasi merupakan unsur yang mengaitkan fungsi-fungsi manajemen yang terdiri dari perencanaan, pengoperasian dan sangat dibutuhkan dalam bidang pendidikan khususnya dalam informasi status akreditasi.

Akreditasi merupakan hal yang sangat penting untuk peningkatan kualitas lembaga, kualitas guru, kualitas siswa, dan peningkatan administrasi. Penyimpanan arsip dokumen akreditasi dapat dikembangkan dalam bentuk sistem informasi. Dimana informasi yang ada dapat diakses oleh beberapa orang yang terkait. Hal ini dilakukan untuk mencapai tujuan agar memudahkan pihak manajemen dalam melakukan tugas yang kompleks dan mendetail.

MI Negeri Kampungbaru adalah salah satu sekolah yang ada di Kecamatan Tanjunganom Kabupaten Nganjuk yang masih menggunakan sistem pengarsipan data akreditasi secara manual.Permasalahan yang terjadi di MI Negeri Kampungbaru Kabupaten Nganjuk saat ini adalah lamanya waktu untuk mencari data yang diarsipkan dalam map \& harus membuka lembar per lembar untuk menemukan data yang diinginkan, data yang dicari kadang tidak lengkap dan bahkan ada data yang hilang. Hal ini disebabkan karena data belum tersimpan dalam basis data.

\section{Kerangka Teori}

\subsection{Landasan Teori}

a. Definisi Sistem

Mudrick dan Ross (1993) mendefinisikan sistem sebagai perangkat elemen yang digabungkan satu dengan lainnya untuk suatu tujuan bersama. Sementara definisi sistem dalam kamus Webster's Unbriged adalah elemen-elemen yang saling berhubungan dan membentuk satu kesatuan atau organisasi.

b. Definisi Sistem Informasi

Menurut (Muslihi, Adrianto. 2013) Sistem Informasi adalah data yang dikumpulkan, dikelompokkan dan diolah sedemikian rupa sehingga menjadi sebuah satu kesatuan informasi yang saling terkait dan saling mendukung sehingga menjadi suatu informasi yang berharga bagi yang menerimanya. Atau dalam pengertian lainnya, Sistem Informasi merupakan kumpulan elemen yang saling berhubungan satu sama lain yang membentuk satu kesatuan untuk mengintegrasikan data, memproses dan menyimpan serta mendistribusikan informasi.

c. Pengarsipan

Menurut Kamus Umum Bahasa Indonesia (Hasan Alwi,2003), arsip adalah simpanan surat-surat penting. Berdasarkan pengertian ini, tidak semua surat dikatakan arsip.

d. Akreditasi

Sekolah merupakan suatu lembaga untuk belajar dan mengajar serta tempat menerima dan memberi pelajaran (menurut KBBI). Sebuah sekolah akan bermutu jika terdapat pengakuan dan penilaian dari beberapa pihak yang berwenang yang disebut akreditasi sekolah/madrasah.

Dalam Akreditasi Sekolah/Madrasah terdapat 8 Standar Pendidikan. 8 Standar Pendidikan atau 8 Standar Nasional Pendidikan merupakan kriteria minimal dalam pelaksanaan sistem pendidikan nasional yang terdiri dari Standa Isi, Standar Proses, Standar Kompetensi Lulusan, Standar Pendidik dan Tenaga Kependidikan, Standar Sarana Prasarana, Standar Pengelolaan, Standar Pembiayaan, Standar Penilaian. 
e. Basis Data

Sistem basis data adalah sistem terkomputerisasi yang tujuan utamanya adalah memelihara data yang sudah diolah atau informasi tersedia saat dibutuhkan. Pada intinya basis data adalah media untuk menyimpan data agar dapat diakses dengan mudah dan cepat.

f. Mysql

MySQL (My Structure Query Language) adalah salah satu DataBase Management System (DBMS) dari sekian banyak DBMS seperti Orancle, MS SQL,Postagre SQL, dan lainnya.MySQL berfungsi untuk mengolah database menggunakan bahasa SQL. MySQL bersifat open source sehingga kita bisa menggunakan secara gratis. Pemrograman PHP juga sangat mendukung/support dengan database MySQ. (Anhar,ST:2010).

g. PHP

PHP singkatan dari PHP:Hypertext Preprocessor yaitu:bahasa pemrograman web server-side yang bersifat open source.PHP merupakan script yang terintegrasi dengan HTML dan beberapa server (server side HTML embedded scripting).PHP adalah scrip yang di gunakan untuk membuat halaman website yang dinamis.Dinamis berarti halaman yang akan di tampilkan dibuat saat halaman itu di minta oleh client.Mekanisme menyebabkan informasi yang di terima client selalu yang terbaru up to date. Semua script PHP dieksekusi pada server di mana script tersebut di jalanka. (Anhar,ST:2010).

h. DFD

Data Flow Diagram (DFD) merupakan diagram yang mengunakan notasinotasi atau simbol-simbol untuk mengambarkan sistemjaringan kerja antar fungsifungsi yang berhubungan satu sama lain dengan aliran dan penyimpanan data.DFD terdiri dari diagram konteks (context diagram) dan diagram rinci (level diagram).Menurut Jogiyanto HM (2005), DFD yang pertama kali digambar adalah yang level teratas yaitu context diagram. Dari context daiagram ini kemudian akan digambar dengan lebih terinci lagi yang disebut dengan overview diagram (level 0 ). Tiap proses di overview diagram akan digambar secara lebih terinci lagi dan disebut dengan level 1 . Tiap proses di level 1 digambar kembali dengan lebih terinci lagi dan disebut dengan level 2 dan seterusnya sampai tiap-tiap proses tidak dapat digambar lebih terinci lagi.(Nuning, Cahyaningrum:2013).

\subsection{Pustaka Rujukan}

Dalam pustaka rujukan ini, penulis mencoba melakukan pemetaan penelitian terkait dengan E-Arsip. Adapun hasil dari pemetaan tersebut antara lain :

\begin{tabular}{|l|l|l|l|}
\hline $\begin{array}{c}\text { Penulis } \\
\text { dan Tahun }\end{array}$ & $\begin{array}{l}\text { Eva Khudzaeva } \\
(2014)\end{array}$ & $\begin{array}{l}\text { Noviana Catur } \\
\text { Wulan Saputri } \\
(2015)\end{array}$ & $\begin{array}{l}\text { Daniel Dinata } \\
\text { Chandra, dkk } \\
(2014)\end{array}$ \\
\hline Judul & $\begin{array}{l}\text { Rancang } \\
\text { bangun sistem } \\
\text { arsip akreditasi }\end{array}$ & $\begin{array}{l}\text { Sistem informasi } \\
\text { akreditasi berbasis } \\
\text { e-arsip untuk } \\
\text { menunjang } \\
\text { persiapan akreditasi }\end{array}$ & $\begin{array}{l}\text { Sistem informasi } \\
\text { dokumentasi borang } \\
\text { akreditasi }\end{array}$ \\
\hline
\end{tabular}




\begin{tabular}{|l|l|l|l|}
\hline Kelebihan & $\begin{array}{l}\text { Mempermudah } \\
\text { dalam } \\
\text { penyimpanan } \\
\text { dan pencarian } \\
\text { akreditasi }\end{array}$ & $\begin{array}{l}\text { Memberikan } \\
\text { kemudahan dalam } \\
\text { pengelolaan dan } \\
\text { manajemen arsip }\end{array}$ & $\begin{array}{l}\text { Membantu proses } \\
\text { penyusunan dan } \\
\text { dokumentasi } \\
\text { dokumen borang } \\
\text { akreditasi }\end{array}$ \\
\hline Kekurangan & $\begin{array}{l}\text { Data diarsipkan } \\
\text { di akhir } \\
\text { semester }\end{array}$ & $\begin{array}{l}\text { Penyimpanan data } \\
\text { dilakukan dalam } \\
\text { bentuk } \\
\text { pengunggahan } \\
\text { dokumen yang } \\
\text { standar }\end{array}$ & $\begin{array}{l}\text { Hanya data guru } \\
\text { dan siswa saja yang } \\
\text { tersimpan pada } \\
\text { database, } \\
\text { selebihnya } \\
\text { disimpan dalam } \\
\text { bentuk dokumen }\end{array}$ \\
\hline
\end{tabular}

\section{Metodologi}

\subsection{Alat dan Bahan}

Bahan penelitian yang digunakan dalam proses penelitian ini berasal melalui wawancara kepala sekolah di MI Negeri Kampungbaru Kabupaten Nganjuk.Dewan guru, petugas TU, studi pustaka,jurnal, artikel dan buku pendukung.

Dalam melakukan penelitian ini, alat yang di gunakan untuk keberhasilan penelitian adalah sebagai berikut:

a. Leptop/ Komputer dengan spesifikasi Prosesor Intel(R) core TM) i3-2350M CPU @ $2,30 \mathrm{GHz} 2,30 \mathrm{GHz}$

b. Installed memory (RAM): 2,00 GM (1,80 GB usable)

c. System type: 32-bit Operating System

Software atau perangkat lunak yang di butuhkan untuk mengimplementasikan rancangan yang telah dibuat adalah:
a. Web Browser
b. XAMPP versi v3.0.2
c. PHP dan Mysq1
d. Google Chrome atau Mozilla Firefox

\subsection{Prosedur Penelitian}

Untuk mencapai tujuan dari penelitian, terutama dalam pengumpulan data serta pengetahuan untuk mendukung proses penelitian ini digunakan metode sebagai berikut:

a. Wawancara

Tanya jawab secara langsung kepada Kepala MI Negeri Kampungbaru.

b. Observasi

Yaitu pengamatan secara langsung untuk memperoleh informasi yang diperlukan

c. Pustaka

Pengumpulan data dari buku, materi dan sumber-sumber terpercaya serta yang berhubungan dengan penelitian.

d. Analisis Sistem Lama

Alur pengarsipan akreditasi di MI Negeri Kampungbaru sebagai berikut:

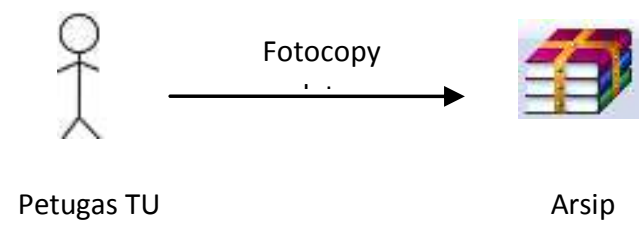

Gambar 3.2.1. Alur sistem lama 
Dari gambar diatas dapat dijelaskan bahwa sistem saat ini petugas TU hanya memfotocopy data akreditasi kemudian diarsipkan kedalam map dan ditaruh didalam rak lemari.

\section{Pembahasan}

\subsection{Perancangan Sistem Baru}

Analisa sistem baru yang dibutuhkan adalah sistem yang bisa mengaplikasikan sistem tentang pengarsipan data akreditasi, oleh karena itu sistem yang dibuat harus mampu memenuhi kebutuhan.

Pemakaian dalam proses input data, menghapus data, mencari data yang dibutuhkan oleh MI Negeri Kampungbaru, sistem baru yang dihasilkan yaitu :

1. Data yang awalnya masih manual akan diubah menjadi komputerisasi dengan adanya sistem.

2. Meminimalisir waktu pada saat pemasukan data dan mengurangi penumpukan data.

3. Proses pencarian data akan lebih mudah dan cepat karena semua data akan dikelompokkan.

4. Alur pengarsipan data akreditasi di MI Negeri Kampungbaru yang diusulkan adalah sebagai berikut:

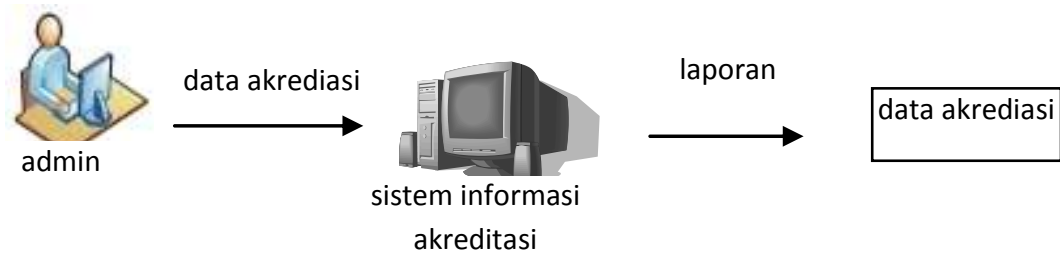

Gambar 4.1.1. Alur yang di usulkan

\subsection{Perancangan Interface Aplikasi}

Perancangan interface aplikasi Sistem Informasi Pengarsipan Akreditasi ini di bangun dengan menggunakan bahasa pemprogaman PHP Mysql.Adapun sebagian bentuk perancangan form yang dibutuhkan adalah sebagai berikut:

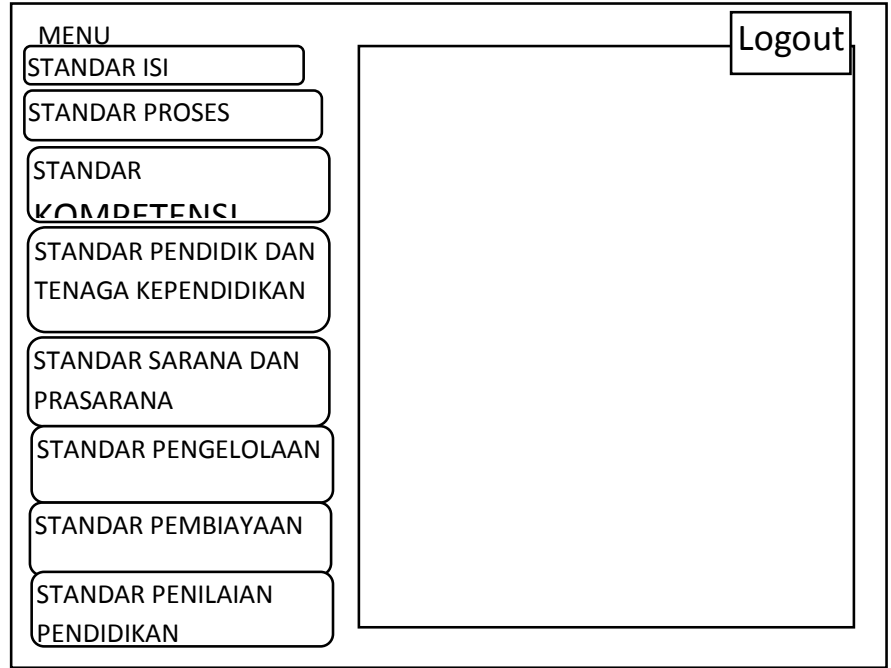

Gambar.1 :Perancangan Form Utama 


\begin{tabular}{|l|l|l|l|l|}
\hline \multicolumn{2}{|l|}{ STANDAR ISI } & & & \multicolumn{2}{l|}{ Cari } \\
\hline & & & & \\
\hline & & & & \\
\hline & & Tambal Habus & Simpa Cetak \\
\hline
\end{tabular}

Gambar.2 :Perancangan Form Standar Isi

\subsection{Hasil Interface Aplikasi}

Setelah dilakukan perancangan interface, dilakukan pengujian untuk melihat apakah hasil perancangan dapat berjalan sesuai harapan. Adapun sebagian hasil yang didapatkan adalah sebagai berikut :

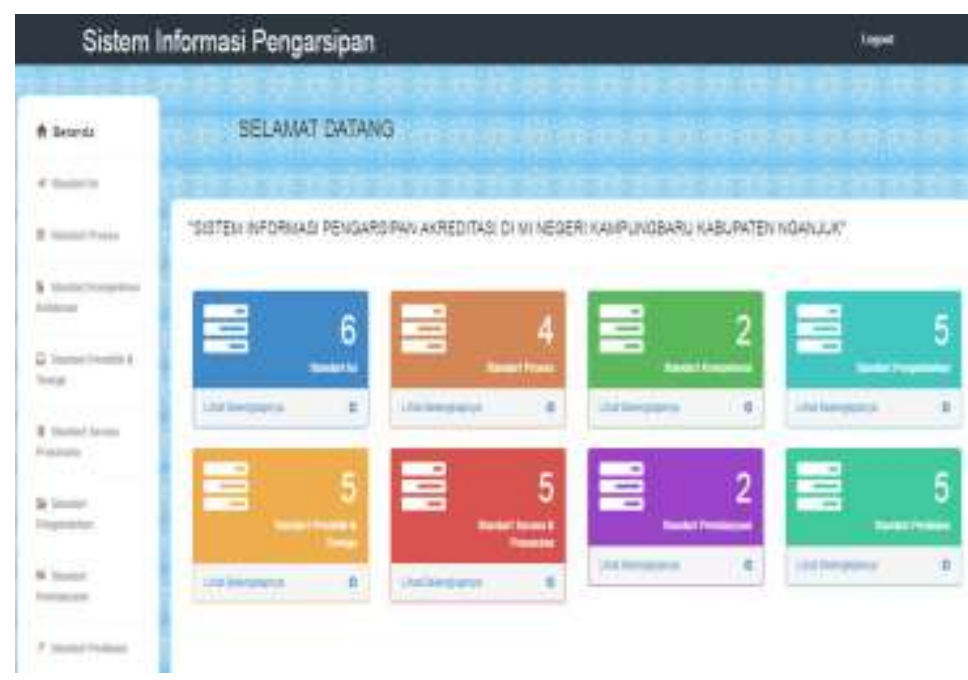

Gambar 4.3 : Tampilan Form Utama

OATA STANDART IS!

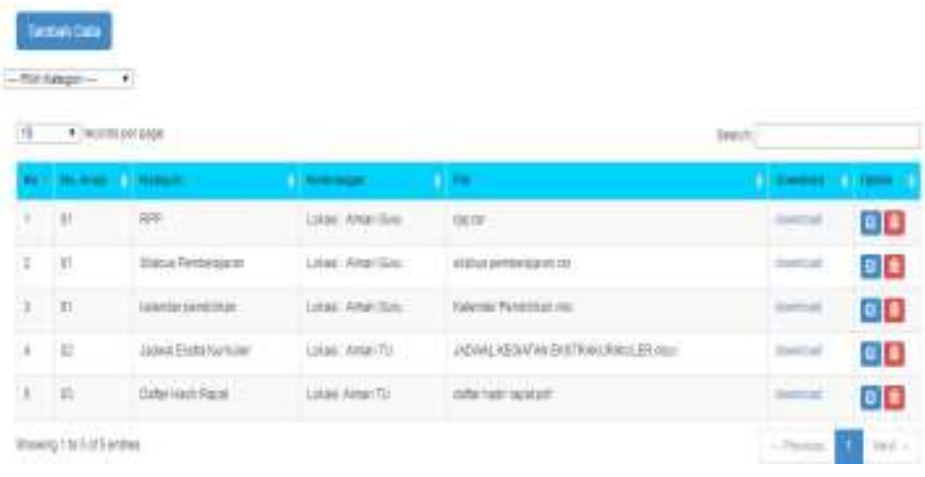

Gambar 4.4 : Tampilan Form Standart Isi 


\section{Penutup} lain :

Berdasarkan hasil pembahasan, penulis dapat mengambil beberapa kesimpulan antara

1. Pengarsipan adalah suatu proses kegiatan atau proses pengaturan mulai dari penerimaan, pencatatan, penyimpanan dengan menggunakan sistem tertentu serta menemukan kembali data dengan cepat dan tepat.

2. Dengan adanya sistem pengarsipan tersebut dapat meminimalisir kehilangan data akreditasi dan dapat membantu kinerja dalam hal efisiensi waktu yang awalnya masih dilakukan secara manual.

3. Berdasarkan aplikasi sistem pengarsipan data akreditasi,

a. Proses pencarian data menjadi lebih cepat karena semua data akreditasi akan dikelompokkan ke dalam standar-standar akreditasi.

b. Dan dengan adanya aplikasi sistem pengarsipan data akreditasi ini dapat mengurangi penumpukan data atau berkas dalam bentuk kertas. 


\section{DAFTAR PUSTAKA}

Alwi, Hasan.2003. Kamus Besar Bahasa Indonesia. Jakarta : Balai Pustaka

Anhar,ST. Anindhita.2010. Panduan Menguasai PHP dan MySQL Secara Otodidak. Jakarta selatan: Mediakita

Cahyaningrum, Nuning. 2013. Pengembangan dan Analisis Sistem Informasi Pengarsipan Surat Masuk dan Surat Keluar di SMK Batik Terbaik Purworejo. Jurnal Informatika. Jurusan Pendidikan Teknik Elektronika. Fakultas Teknik. Universitas Negeri Yogyakarta.

Dinata, Daniel, dkk. 2013. Sistem Informasi Dokumentasi Borang Akreditasi. Jurnal Informatika. Program Studi Sistem Informasi. STMIK GI MDP.

Khudzaeva, Eva. 2014. Rancang Bangun Sistem Arsip Akreditasi. Jurnal Informastika. Jurusan Sistem Informasi. Fakultas Sains dan Teknologi. Universitas Negeri Syarif Hidayatullah.

Muslihi, Adrianto. 2013. Pengembangan Sistem Informasi Akreditasi. Jurnal Informatika. Jurusan Elektro. Program Studi Teknik Informatika. Universitas Hasanuddin.

Noviana. 2015. Sistem Informasi Akreditasi Prodi (SIAKAP) Berbasis E-Arsip untuk Menunjang Persiapan Akreditasi Prodi. Jurnal Informatika. Jurusan Manajemen. Fakultas Ekonomi. Universitas Negeri Semarang.

Taurens, Diki. 2014. Pembangunan Sistem Informasi Sebagai Penunjang Peningkatan Akreditasi di SDN Pawenang Cianjur. Jurnal Informatika. Jurusan Teknik Informatika. Cianjur.

Zulistiyani. 2013. Sistem Informasi Pembayaran SPP Di SMP Ma'rifah 3 Kebumen. 